\title{
Correction to: The Use of Botulinum Toxin for Treatment of Spasticity
}

Sheng Li and Gerard E. Francisco

\section{Correction to: \\ Chapter "The Use of Botulinum Toxin for Treatment of Spasticity" in: S. Li and G. E. Francisco, Handbook of Experimental Pharmacology, https://doi.org/10.1007/164_2019_315}

The chapter was inadvertently published without a more specific title according to SEO guidelines. A chapter title needs to be understandable when seen as a standalone item, e.g. on PubMed. The chapter title has now been corrected as 'The Use of Botulinum Toxin for Treatment of Spasticity'.

The original article was corrected. 